\title{
Género y antiimperialismo en Ancho Mar de los Sargazod de Jean Rhys
}

Gender and anti-imperialism in Jean Rhys'Wide Sargasdo Sea

\section{Gênero e anti-imperialismo em Wide Sargasso Sea de a autora Jean Rhys}

Aida Chacón-Castellanos

Universidad Autónoma de México

Recibido: 3/4/2015. Aceptado: 20/7/2015

http://dx.doi.org/10.15359/tdna.31-58.10

\section{Resumen}

Concuerdo con Maricruz Castro (2009), quien señala que género es un concepto mediante el cual quedan manifiestas las construcciones culturales alrededor de la mujer y de lo femenino, así como también del hombre y lo masculino. Considero que la autora Jean Rhys puede brindar una visión de primera mano sobre el tema no solamente de lo femenino sino también del prejuicio racial y el discurso imperialista a partir del cual se construye la identidad del otro. Fundo mi acercamiento en Wide Sargasso Sea, Ancho mar de los Sargazos, de Rhys. La

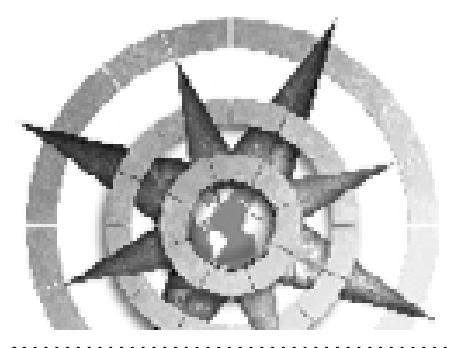

construcción de la figura femenina, ligada a la locura y el prejuicio racial, desde el punto de vista imperialista, son elementos que la autora trata de desvincular desde su muy particular narrativa.

Palabras clave: Antiimperialismo latinoamericano, Jean Rhys, Ancho mar de los Sargazos, escritura de mujeres, literatura latinoamericana, racismo y otredad, Temas de Nuestra América

\section{Abstract}

I agree with Maricruz Castro (2009) who notes that "gender" is a concept by which the cultural construction about woman and the feminine and man and the masculine, become evident. I believe that the author Jean Rhys can provide a vision not only about the feminine side but also about the racial prejudice and the imperialist discourse from which the otherness I base my approach in Jean Rhys' novel Wide Sargasso Sea, in which the 
construction of the female figure is linked to madness and racial prejudice. From an imperialist point of view of this discourse, those are elements that the author tries to decouple from its very particular narrative.

Keywords: Latin American Antiimperialism, Jean Rhys, Wide Sargasso Sea, Women's Writing, Latin American Literature, Racism and Otherness, Temas de Nuestra América

\section{Resumo}

Eu concordo com Maricruz Castro (2009), quanto diz que "gênero" é um conceito pelo qual construções culturais em torno da mulher e do feminino, assim como do homem e do o masculino se manifestam. Eu acredito que a autora Jean Rhys pode fornecer em primeira mão, uma visão sobre conceito do que é feminino asim do que é preconceito racial, em discurso imperialista atraves do qual a identidade do outro é construída. Baseio meu abordagem no romance Wide Sargasso Sea, da Jean Rhys. A construção da figura feminina ligada à loucura e ao preconceito racial, desde o ponto de vista imperialista, são elementos que Jean Rhys tenta descolar em sua narrativa.

Palavras chave: Antiimperialismo Latino-Americano, Jean Rhys, Wide Sargasso Sea, literatura latinoamericana, escrita feminina, racismo e alteridade, Temas de Nuestra América
A lo largo de la mi vida profesional y académica me he topado en innumerables ocasiones con una pregunta muy enigmática: ¿para qué sirve la literatura?

Hasta el momento no he podido resolver, ni para mí misma, este cuestionamiento y sin embargo, considero que una virtud de la literatura es precisamente su carácter polisémico, mismo que me permite hacer, en este lugar y en este momento, una lectura profunda que brinda la interpretación de un texto narrativo cuyo valor estético le otorga un lugar en la historia de la literatura inglesa y caribeña.

Para dar inicio a esta breve análisis de Wide Sargasso Sea me gustaría empezar haciendo una reseña sobre quién es Jean Rhys y por qué es importante saberlo. Su nombre real fue Ella Gwendolen Rees Williams y nació a finales del siglo XIX en Martinica. Creció en el Caribe sin ser aceptada por la sociedad criolla que la rodeaba y posteriormente viajó a Inglaterra para terminar sus estudios.

Debido al fallecimiento de su padre interrumpió este proyecto e incursionó como corista sin conseguir éxito alguno. Los problemas económicos se convirtieron en una realidad y también el rechazo de la sociedad europea por sus orígenes antillanos. 
Con su acercamiento a la literatura Rhys conoció un mundo bohemio que la arrastraría al alcoholismo por el resto de su vida. Pobreza y marginación determinaron su vida tanto en su isla natal como en Inglaterra y también prácticamente toda su obra literaria. Después de un largo silencio de más de veinte años Jean Rhys sorprendió al mundo con su obra maestra Wide Sargasso Sea.

Conocer la vida de esta autora es fundamental debido a que, si nos ceñimos como punto de partida propuesto por Maricruz Castro (2009), donde señala que género es un concepto mediante el cual quedan manifiestas las construcciones culturales alrededor de la mujer y de lo femenino, así como también del hombre y lo masculino, tenemos que la autora puede brindar una visión de primera mano sobre el tema, no solamente de lo femenino sino también del prejuicio racial y el discurso imperialista a partir del cual se construye la identidad del otro.

En otras palabras, Jean Rhys incursiona en la escritura a partir del auto-reconocimiento que le permite dimensionar las contradicciones individuales socio-culturales. En palabras de Elizabeth Vivero (2011: $\mathrm{s} / \mathrm{p}$ ): "La literatura, el texto literario, debe abrirse a su dimensión social en tanto producto cultural que coadyuva a la formación de un discurso en torno al género".

Wide Sargasso Sea es una propuesta que responde a un personaje al que se le fue negada el habla en Jane Eyre de Chalotte Brontë. La voz ausente de Bertha Mason, la primera esposa de Rochester, es la voz que da vida a Wide Sargasso Sea y que, paradójicamente, vuelve a ser silenciada en esta obra para dar paso a la voz imperialista que roba la identidad de nuestra protagonista.

Wide Sargasso Sea (1966), se crea a partir de la necesidad de reivindicación de la figura femenina que la autora percibe indispensable en el discurso narrativo. La construcción de la figura femenina, ligada a la locura y el prejuicio racial, desde el punto de vista imperialista son elementos que la autora trata de desvincular desde su muy particular narrativa.

Asimismo, la construcción conceptual del otro, lejano y situado en el Caribe, está deliberadamente sometida a una visión también imperialista, que la autora utiliza como pretexto para la concepción de Wide Sargasso Sea. Jean Rhys (1990) construye, a partir del discurso narrativo, una contestación antiimperialista que pretende enfrentar esa visión 
imperial (en Jane Eyre), con la visión propia de una nación colonizada.

Debo señalar que la obra magistral del Rhys aunque se trata de una reconstrucción de un personaje enigmático de Brontë, representa en sí misma una obra autónoma, con una voz contundente y que plasma una interpretación de sí mismo desde la mirada del colonizado y sin dejar a un lado la mirada del colonizador.

Desde el punto de vista de género, la voz de Bertha Mason representa la búsqueda constante de identidad, misma que le es arrebata desde temprana edad y que será siempre violentada a lo largo de su vida y hasta llegar a su muerte. En este sentido es que Judith Butler (2006), señala que el texto literario se convierte en una especie de norma cultural que imprime, por medio de la representación, la posición que deben guardar los sexos.

Es a partir de esta perspectiva de género que Rhys establece también un discurso claramente antiimperialista que pretende la reivindicación de ese otro colonizado cuya identidad se construye a partir del prejuicio y el racismo imperialista manifestado por una sociedad esclavista criolla y también europea.
El prejuicio es definido por Olivia Gall (2014), como:

una actitud, un juicio o un sentimiento acerca de una persona, que proviene de una generalización de las actitudes o creencias que se tienen acerca del grupo al que esa persona pertenece. Esta manera de pensar promueve la ignorancia, degrada el conocimiento, excluye en lugar de incluir, tensa las relaciones y propicia el rechazo entre los seres humanos (2014: p. 8).

A lo largo de la novela de Rhys podremos apreciar numerosos ejemplos sobre cómo el prejuicio inicia por segregar al otro hasta llegar a la violencia y exterminio de un grupo social determinado.

Por otro lado, el estereotipo es señalado como el antecedente directo o aquello que da origen al prejuicio. Nuevamente Gall apunta que el estereotipo es una forma de asignar rasgos tanto positivos como negativos a un grupo entero de personas. Ejemplos cotidianos de estereotipos podemos encontrar en cualquier forma del discurso; al decir que los negros son "pachangueros", las costeñas muy "ardientes", estamos creando estereotipos humanos. Los estereotipos tienen características 
muy particulares que se pueden resumir en ocho aspectos:

1. son factualmente incorrectos

2. están basados en el prejuicio

3. son ilógicos al estar basados en rumores

4. propician que sus portadores sean irracionalmente resistentes a otras ideas

5. exageran las diferencias entre los grupos

6. son etnocéntricos

7. se fundamentan en el biologicismo

8. subestiman la variabilidad del otro.

La historia de Antoinette, quien más adelante será llamada Bertha Mason como una negación más a su identidad, en Wide Sargasso Sea está situada en 1830, en una sociedad llena de prejuicios raciales que no solamente van en un sentido, del opresor al oprimido, sino también al contrario. Numerosos ejemplos sobre las ideas imperantes de la época, que me atrevería a decir que aún permanecen hasta nuestros días, se encuentran a lo largo de la narrativa de Rhys. A este respecto, el mismo
Fanon mencionaba que "El negro que quiere blanquear a su raza es tan desgraciado como el que predica el odio contra el negro". (1973: p. 9).

Antoinette Coswey es una chica que crece dentro de una sociedad criolla profundamente odiada por los esclavos recientemente liberados. La novela se desarrolla entre Jamaica y Martinica. La señorita Coswey narra su infancia en Jamaica a lado de su hermano y su madre, en una finca venida a menos tras la muerte del padre. El abuelo de Antoinette liberó a los esclavos tal como fue ordenado tras la abolición de la esclavitud, sin embargo, la familia sufrió las consecuencias de su pasado esclavista y por muchas costumbres que aún imperaban en la región y entre la gente "blanca", por ejemplo, Christophine, la nana negra de Antoinette: "Christophine fue el regalo de bodas que me hizo tu padre, uno de los regalos que me hizo. Pensó que me gustaría tener una muchacha de la Martinica. No sé qué edad tenía cuando la trajeron a Jamaica, muy joven sería. Y no sé qué edad tiene ahora ¿Importa?" (1990: p. 23).

Como puede observarse en el ejemplo anterior, aun cuando la familia Cosway carecía del apoyo masculino en una sociedad patriarcal y que esta situación los tenía sumidos en 
la pobreza, sus ideas de colonizadores permanecían.

El odio de los esclavos liberados hacia la gente blanca se recrudecía alrededor de la infancia de Antoinette pues al perder el estatus de ricos, la diferencia de color se volvía nula y el "respeto" hacia ellos se desvaneció. Estas ideas también muestran cómo los mismos negros construían su concepto sobre sí mismos.

... se decía que éramos pobres como ratas. Que comíamos pescado salado porque no teníamos dinero para pescado fresco. Que la casa era vieja y con tantas goteras que, cuando llovía, teníamos que ir de un lado a otro poniendo calabazas para que en ellas cayera el agua de la lluvia. Había en Jamaica mucha gente blanca. Gente blanca de veras, que tenía dinero de oro. Y esa gente blanca ni nos miraba, y nadie nos había visto con ella. Los blancos de los viejos tiempos no son más que negros blancos, ahora los negros negros valen más que los blancos negros (p. 27).

¿Cuál era la forma en la que se concebían como negros los propios negros?, a este respecto, se puede dilucidar que aquellos valores asociados con la pobreza, carencias, desamparo, etc., son las mismas que están asociadas con el "ser negro" y por ende las que se usarán para definir a los "blancos negros".

El prejuicio continúa en el discurso narrativo de la obra pero esta vez en voz del señor Rochester, esposo de Antoinette. Este personaje siempre dará más peso a sus prejuicios que a cualquier evidencia sobre el pasado o presente de su esposa criolla. De igual forma él la desposó por el dote matrimonial que lo salvaría de la mendicidad, pero la idea de casarse con una criolla nunca es del todo agradable.

Subióse la falda de vestido de amazona, y cruzó corriendo la calle. La contemplé con sentido analítico. Se tocaba con un sombrero de tres picos que le sentaba bien. Por lo menos, le sombreaba los ojos, que son excesivamente grandes, y llegan a desconcertar. Tengo la impresión de que nunca parpadee. Quizá sea criolla de puro linaje inglés, pero sus ojos no son ingleses, ni tampoco europeos. ¿Y cuándo comencé a darme cuenta de que mi esposa, Antoinette, era así? Después de salir de Spanish Town, supongo (p. 69).

La cultura caribeña está formada por la enorme confluencia de componentes raciales y étnicos debido al devenir histórico del colonialismo. En esta obra se puede apreciar la visión contrastada de la nación colonizada y colonizadora a partir de 
sus voces narrativas. Jean Rhys experimenta con una propuesta contestataria que pretende reivindicar al personaje de Brontë, Bertha Mason, a partir de la construcción de su historia desde la infancia hasta su llegada a Inglaterra. Jean Rhys hace una importantísima contribución a la narrativa martiniqueña a partir de su obra que pretende también deslindar lo femenino como un elemento de propensión a la locura.

Esta magistral obra, conformada en tres partes, narra en la primera de ellas la infancia de Bertha Mason que está determinada por el prejuicio cultural entre blancos y negros en una pequeña comunidad de Jamaica; la voz narrativa es la propia Mason que lucha por conservar su identidad conformada por la educación de su nana negra y las obligaciones propias de una criolla blanca en una sociedad patriarcal.

En la segunda parte de la novela de Rhys, se escucha la voz del personaje europeo que juzga a partir del desconocimiento de los elementos culturales de la sociedad en la que se establece y reafirma la visión europea que se tiene sobre la gente del Caribe, gente "loca, que no controla sus emociones", cuya religión y magia son muestra de su falta de civilidad y también infunden temor a lo desconocido. Específicamente se trata del vudú o obhá que forma parte importante de la cultura de Antoinette.

Y, por último, en la segunda parte de esta obra se puede apreciar cómo es que, nuevamente, la voz de Bertha Mason es sometida para acallar su necesidad de conservar su identidad. Es lanzada a la locura y destinada a la confinación, el abandono y el silencio por el resto de su vida.

Podrían enumerarse muchos más ejemplos de este tipo a lo largo de la novela pero para acotar solo agregaré que esta novela está escrita desde la necesidad de reivindicación de la figura antillana femenina en el imaginario inglés y que se trata de una de las más representativas novelas del Caribe anglófono del siglo XX.

Hasta aquí sigo sin saber a ciencia cierta para qué sirve la literatura, sin embargo puedo aventurarme a decir que es algo que va más allá de la ficción y que ayuda a representar la realidad de una forma que podamos acercarnos más a ella. 


\section{Referencias bibliográficas}

Brontë, Ch. (2012). Jane Eyre. España: Alianza Editorial.

Buttler, J. (2006). Deshacer el género. (Patricia Soley-Beltrán, Trad.). Barcelona: Paidós.

Castro, M. (2009). Género. En: Mónica Szurmuk, Robert McKee (coord.). Diccionario de Estudios Culturales Latinoamericanos. México: Siglo XXI, Instituto Mora.

Fanon, F. (1973). Piel negra, máscaras blancas. Argentina: Editorial Abraxas.

Gall, O. (2014). Prejuicio y Racismo. En: Fanny Blanck (coord.). El prejuicio. México: FCE (en prensa).

Rhys, J. (1990). Ancho mar de los Sargazos. (Andrés Bosch, Trad.). España: Anagrama. 2a edición.

Vivero, E. (2011). Literatura y género. Espéculo. Revista de estudios literarios. Universidad Complutense de Madrid. $\mathrm{N}^{\circ}$ 47. Recuperable en: http:// www.ucm.es/info/especulo/numero47/ligenero.html 